Revista Tecné, Episteme y Didaxis: TED. Año 2014, Número Extraordinario. ISSN Impreso: 0121-3814, ISSN web: 2323-0126 Memorias, Sexto Congreso Internacional sobre Formación de Profesores de Ciencias. 08 al 10 de octubre de 2014, Bogotá

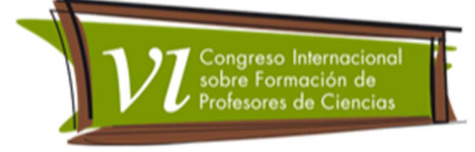

\title{
As interações discursivas e a construção de argumentos: investigando um trabalho de campo
}

Grandi, Luziene Aparecida' e Motokane, Marcelo Tadeu²

Categoria 2. Trabalho de investigação

\section{Resumo}

A linguagem argumentativa pode ser considerada uma das principais características do processo de construção do conhecimento científico. Todavia, ela não é estimulada em todos os ambientes educativos, como os espaços nos quais se estabelece a aprendizagem por meio do discurso oral. De tal modo, o objetivo deste trabalho é verificar que tipos de interações discursivas se estabelecem entre monitores e alunos durante um trabalho de campo. Para isso, a atividade foi videogravada e transcrita. A análise das transcrições ocorreu com base no Padrão de Argumentação de Toulmin e na verificação das características das interações discursivas presentes. Foram obtidas duas categorias relacionadas à construção do argumento pelo monitor e à tentativa de construção do argumento pelo aluno, pois as falas dos monitores predominaram durante toda a atividade, direcionando discurso.

\section{Palavras-chave}

Trabalho de campo, interações discursivas, discurso oral.

\section{Objetivos}

Verificar que tipos de interações discursivas se estabelecem entre monitores e alunos durante uma atividade de trabalho de campo em uma área reflorestada.

\section{Marco teórico}

A linguagem argumentativa pode ser considerada uma das principais características do processo de construção do conhecimento científico (Sasseron \& Carvalho, 2011), pois é por meio da argumentação que cientistas

\footnotetext{
1 Universidade de São Paulo, Departamento de Biologia - FFCLRP. luzienegrandi@gmail.com 2 Universidade de São Paulo, Departamento de Biologia - FFCLRP. mtmotokane@ffclrp.usp.br
} 
Revista Tecné, Episteme y Didaxis: TED. Año 2014, Número Extraordinario. ISSN Impreso: 0121-3814, ISSN web: 2323-0126 Memorias, Sexto Congreso Internacional sobre Formación de Profesores de Ciencias. 08 al 10 de octubre de 2014, Bogotá

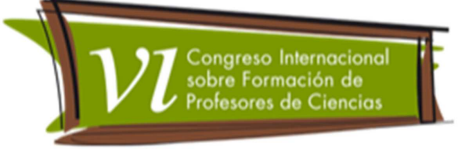

convencem seus pares sobre a importância dos seus trabalhos (Latour \& Woolgar, 1997).

A argumentação pode ser entendida como "a capacidade de relacionar dados e conclusões, de avaliar enunciados teóricos à luz dos dados empíricos ou procedentes de outras fontes" (Jiménez \& Díaz, 2003, p. 360). De forma mais ampla, Sasseron e Carvalho (2011 , p. 100) a entendem "como todo e qualquer discurso em que aluno e professor apresentem suas opiniões em aula, descrevendo ideias, apresentando hipóteses e evidências, justificando ações ou conclusões a que tenham chegado, explicando resultados alcançados". Pode também ser considerada como uma estratégia de raciocínio que conduz à aprendizagem (Jiménez et al, 2000).

Entretanto, para estimular este raciocínio, é importante entender como ocorre o processo de argumentação (Sasseron \& Carvalho, 2011). Uma das maneiras de entender este processo é verificando como dados, justificativas e conclusões são construídos por meio de interações discursivas e como esses elementos se articulam em um argumento, considerando muitas vezes refutadores, garantias em conhecimentos científicos e qualificadores modais. Estes são os elementos apresentados no Padrão de Argumentação de Toulmin (2001) que, por apresentar essas características, se torna uma importante feramenta para identificar, no discurso, o argumento construído durante o ensino de ciências/biologia.

O estudo do discurso nas aulas de ciências auxilia na compreensão dos processos de aprendizagem (Sasseron \& Carvalho, 2011; Jiménez \& Díaz, 2003; López \& Jiménez, 2007). Cazden (1991 apud Jiménez \& Díaz, 2003) considera o discurso escolar como um sistema de comunicação implantado pelo professor e os significados concretos que um docente e uma classe realizam. A expressão oral torna-se, então, decisiva, porque a instrução procede, em grande totalidade, por meio da linguagem falada e porque a aprendizagem se demonstra igualmente por meio da mesma.

Por isso, é necessário atentar para a formulação do argumento oral. Este ocorre em um tempo muito curto, o que exige dos locutores e interlocutores do discurso um raciocínio muito rápido para articular elementos estruturantes de argumentos em suas falas.

Devido a esta dinâmica exigida na construção de argumentos por meio do discurso oral, geralmente a sua produção é ínfima. É preciso pensar em atividades que tenham o potencial para estimular a oralidade e mediar a construção do conhecimento científico do aluno, como os trabalhos de 
Revista Tecné, Episteme y Didaxis: TED. Año 2014, Número Extraordinario. ISSN Impreso: 0121-3814, ISSN web: 2323-0126 Memorias, Sexto Congreso Internacional sobre Formación de Profesores de Ciencias. 08 al 10 de octubre de 2014, Bogotá

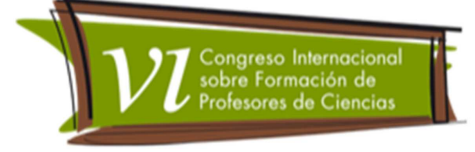

campo em ambientes naturais. Nos trabalhos de campo há uma maneira peculiar de se fazer delimitações e observar o ambiente de estudo, assim como o manuseio de instrumentos para a obtenção de dados é bem específico. Por isso, quando estudantes são mobilizados a participarem deste tipo de atividade interagindo com situações que objetivem a resolução de problemas, existe um grande potencial para que ocorra a aproximação e introdução na cultura da Ciência, incluindo a comunicação por meio da linguagem argumentativa.

\section{Metodologia}

Considerando a sucessão ecológica como um tema integrador de vários conhecimentos no ensino de ciências, um trabalho de campo foi elaborado para ser realizado em uma área reflorestada da Universidade de São Paulo, campus da cidade de Ribeirão Preto, e no Laboratório de Ensino de Biologia. Foi aplicado a uma turma de 25 alunos (do sétimo ano do ensino fundamental) por dois monitores (alunos do curso de Ciências Biológicas da mesma universidade).

Por meio do estudo de parcelas, o trabalho de campo objetivou a comparação de características desse mesmo reflorestamento em locais cujo plantio de mudas ocorreu em épocas diferentes (o manejo e as espécies plantadas também não foram iguais).

A atividade foi filmada, transcrita e analisada. Considerando as interações discursivas entre monitor-aluno, monitor-monitor e aluno-aluno, as falas dos participantes foram agrupadas em categorias. O Padrão de Argumentação de Toulmin (TOULMIN, 2001) foi utilizado para verificar se as falas dos participantes apresentavam características semelhantes as dos elementos constituintes desse padrão: dado, justificativa, apoio, conclusão, qualificador modal e refutação.

\section{Resultados e discussão}

Por meio das análises das transcrições, características diferentes referidas às falas dos participantes puderam ser observadas nas interações discursivas que compõem o trabalho de campo. Se atendo a essas características foi possível relacioná-las a duas categorias: "Tentativa de construção do argumento pelo aluno" e "Construção do argumento pelo monitor" (Tabela 1). 
Revista Tecné, Episteme y Didaxis: TED. Año 2014, Número Extraordinario. ISSN Impreso: 0121-3814, ISSN web: 2323-0126 Memorias, Sexto Congreso Internacional sobre Formación de Profesores de Ciencias. 08 al 10 de octubre de 2014, Bogotá

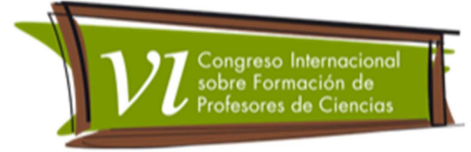

Tabela 1. Características das interações discursivas presentes no trabalho de campo.

\begin{tabular}{|c|c|c|}
\hline $\begin{array}{l}\text { CATEGORIAS } \\
\text { CARACTERÍSTICAS } \\
\text { DAS FALAS DOS PARTICIPANTES }\end{array}$ & $\begin{array}{l}\text { TENTATIVA DE } \\
\text { CONSTRUÇĀO } \\
\text { DO } \\
\text { ARGUMENTO } \\
\text { PELO ALUNO }\end{array}$ & $\begin{array}{l}\text { CONSTRUÇÃO } \\
\text { DO } \\
\text { ARGUMENTO } \\
\text { PELO } \\
\text { MONITOR }\end{array}$ \\
\hline $\begin{array}{l}\text { 1. Perguntas dos monitores que desencadeiam respostas } \\
\text { curtas nos alunos }\end{array}$ & & \\
\hline $\begin{array}{l}\text { 2. Conhecimentos prévios dos alunos relacionados ao } \\
\text { que, para eles, representa uma floresta }\end{array}$ & & \\
\hline $\begin{array}{l}\text { 3. Falas dos alunos em resposta às perguntas dos } \\
\text { monitores ou questões que poderiam gerar } \\
\text { argumentos, levantadas pelos próprios alunos }\end{array}$ & & \\
\hline $\begin{array}{l}\text { 4. Interpretações da floresta pelos alunos e/ou } \\
\text { demonstração de curiosidade pelo lugar }\end{array}$ & & \\
\hline 5. Dinâmica entre os monitores & & \\
\hline $\begin{array}{l}\text { 6. Simplificação da explicação dos monitores e/ou suas } \\
\text { concepções acerca de assuntos envolvendo o } \\
\text { trabalho de campo }\end{array}$ & & \\
\hline 7. Monitores como protagonistas & & \\
\hline $\begin{array}{l}\text { 8. Informações que contextualizam historicamente a } \\
\text { Floresta da USP }\end{array}$ & & \\
\hline 9. Informações que caracterizam a área reflorestada & & \\
\hline 10. Dados coletados durante o trabalho de campo & & \\
\hline 11. Dados do argumento construído & & \\
\hline 12. Justificativa & & \\
\hline 13. Conclusão & & \\
\hline
\end{tabular}

\section{Categoria "Tentativa de construção do argumento pelo aluno"}

A categoria "Tentativa de construção do argumento pelo aluno" representa indícios de turnos nos quais essa argumentação poderia ser estimulada.

A característica relacionada às falas dos alunos em resposta às perguntas dos monitores ou questões que poderiam gerar argumentos foi a mais representativa desta categoria, pois argumentos decorrentes da interação discursiva entre monitores e alunos foram construídos nessas situações, ou pelo menos houve a relação de dois elementos estruturais do argumento segundo o modelo de Toulmin (2001), como o dado e a justificativa.

$\mathrm{Na}$ característica "Perguntas dos monitores que desencadeiam respostas curtas nos alunos" e "Conhecimentos prévios" houve a intenção dos 
Revista Tecné, Episteme y Didaxis: TED. Año 2014, Número Extraordinario. ISSN Impreso: 0121-3814, ISSN web: 2323-0126 Memorias, Sexto Congreso Internacional sobre Formación de Profesores de Ciencias. 08 al 10 de octubre de 2014, Bogotá

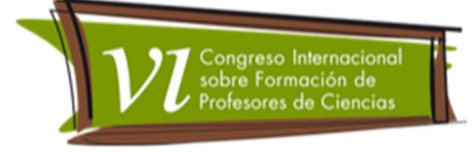

monitores, por meio de perguntas, de oportunizar aos alunos momentos nos quais eles participariam da construção do discurso oral. Contudo, a participação dos alunos não foi muito instigada, pois as perguntas dos monitores requeriam respostas do tipo "sim" ou "não". Não houve a intervenção dos monitores para mediar as respostas dos alunos, possibilitando aos primeiros a oportunidade de se posicionar diante de suas opiniões e aos segundos, a chance de introduzir novos conceitos científicos e significá-los.

Quanto à "Interpretação da floresta pelos alunos e/ou demonstração de curiosidade pelo lugar", os alunos somente deram indícios das áreas da Floresta da USP que acharam mais interessantes como também revelaram as suas expectativas sobre o que encontrar em uma área reflorestada com um dossel formado (animais grandes, por exemplo).

\section{Categoria "Construção do argumento pelo monitor"}

A categoria "Construção do argumento pelo monitor" incluiu agrupamentos de falas que revelaram que os monitores foram os que mais contribuíram com a construção do discurso durante a atividade, conduzindo a sequência e o teor dos assuntos tratados para respaldar a resolução do problema do trabalho de campo.

Essa categoria pode ser justificada pelo predomínio de três características: uma delas foi representativa da interação entre os monitores, na outra os turnos de fala tiveram os monitores como protagonistas do discurso e a última característica esteve relacionada com o que de fato os monitores discutiram com os alunos, simplificando as explicações.

As transcrições evidenciaram que um dos monitores apresentava muito mais falas do que o outro nos episódios nos quais estavam juntos. Entretanto, as poucas interferências do outro monitor eram feitas de forma a direcionar a discussão retomando algum ponto que foi esquecido.

Interações discursivas nas quais as perguntas que os monitores fizeram aos alunos não geraram controvérsias representaram uma estratégia principalmente para atrair a atenção dos alunos ao longo discurso. A simplificação da explicação dos monitores e/ou suas concepções acerca de assuntos envolvendo o trabalho de campo também abarcaram a categoria "Construção do argumento pelo monitor". Percebemos que os monitores sabiam o porquê da metodologia que estavam usando, mas não a aprofundaram para discutir os dados obtidos. Isto pode ser decorrente do 
Revista Tecné, Episteme y Didaxis: TED. Año 2014, Número Extraordinario. ISSN Impreso: 0121-3814, ISSN web: 2323-0126 Memorias, Sexto Congreso Internacional sobre Formación de Profesores de Ciencias. 08 al 10 de octubre de 2014, Bogotá

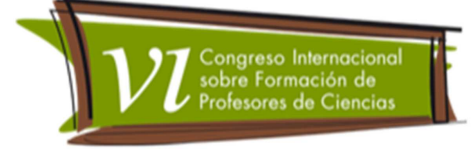

conhecimento científico que eles consideraram importante ensinar aos alunos e, desta forma, simplificaram a sua abordagem.

A categoria em questão foi representada por uma maior quantidade de falas no início do trabalho de campo, em relação à categoria de tentativa de construção do argumento pelo aluno, até mesmo porque os monitores conduziram esse momento da atividade de forma a apresentar mais informações do que promover situações de troca de conhecimento com os alunos. Na área reflorestada, a quantidade de falas relacionadas à construção do argumento pelo monitor foi menor devido aos monitores passarem a maior parte do tempo dando orientações aos alunos sobre como coletar os dados e registrá-los. No momento em que houve a discussão dos dados coletados no trabalho de campo foram os monitores que delinearam todo o discurso para chegarem a uma única conclusão.

O estudo da dinâmica da atividade de campo tornou perceptivel a contribuição de cada interação discursiva de forma a estruturar um argumento mais abrangente ao final da atividade. No primeiro momento houve uma contextualização histórica da Floresta da USP e apresentação de outros elementos que caracterizaram a floresta, contextualizando o problema de campo. No segundo episódio houve a coleta dados os quais, no terceiro episódio, receberam asserções, foram justificados e relacionados a uma conclusão.

\section{Conclusões}

Com base nos resultados e nas análises, pode ser percebida a preocupação dos monitores em cumprir uma tarefa, ou seja, coletar os dados de forma precisa e, posteriormente no laboratório, sistematizar a discussão dos dados coletados. Nesse processo, será que os monitores perceberam que foram os principais responsáveis pela construção de argumentos no decorrer dessas discussões? O que significa argumentar para os monitores?

Estas indagações permitiram que certos aspectos fossem considerados. Se os monitores deram significados diferentes aos da pesquisadora às questões anteriores, o processo envolvendo a orientação dos monitores e a elaboração do guia de campo entregue aos alunos (de forma a garantir o estímulo das habilidades argumentativas destes) tiveram mesmo pouca eficácia. Se o que significa para eles um bom trabalho de campo não condiz com o que foi traçado no guia de campo, poderia levá-los a preterir quaisquer informações ou instruções que não considerassem necessárias. 
Revista Tecné, Episteme y Didaxis: TED. Año 2014, Número Extraordinario. ISSN Impreso: 0121-3814, ISSN web: 2323-0126 Memorias, Sexto Congreso Internacional sobre Formación de Profesores de Ciencias. 08 al 10 de octubre de 2014, Bogotá

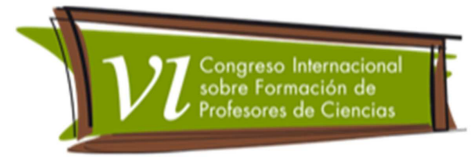

No que diz respeito à estruturação de um argumento em um contexto real no qual várias pessoas interagem discursivamente, o Padrão de Argumentação de Toulmin auxiliou a verificação de elementos estruturantes de argumentos, mas não subsidiou o entendimento relacionado ao que aconteceu na atividade de campo que fez com que os argumentos fossem construídos somente pelos monitores e não por meio da interação aluno-aluno e alunomonitor. Apenas o uso Padrão de Argumentação de Toulmin não foi suficiente para auxiliar o entendimento da dinâmica discursiva da atividade de trabalho de campo, elucidando explicações acerca do contexto de produção dos argumentos.

\section{Referências bibliográficas}

Díaz de Bustamente, J. (2003). Discurso de aula y argumentación em la clase de ciencias: cuestiones teóricas y metodológicas. Enseñanza de las Ciencias, 21(3), 359-370.

Jiménez, M.P., Bugallo, A. \& Duschl, R.A. (2000). "Doing the Lesson" or "Doing Science": Argument in High School Genetics. Science Education, 84, 757792.

Latour, B. \& Woolgar, S. (1997). A vida de laboratório: a produção de fatos científicos. Rio de Janeiro: Relume Dumará.

López, R.R. \& Jiménez, M.P. (2007). Podemos cazar ranas? Calidad de los argumentos de alumnado de primaria y desempeño cognitivo en el estudio de una charca. Enseñanza de las Ciencias, 25(3), 401-414.

Toulmin, E. (2001). Os usos do argumento. São Paulo: Martins Fontes.

Rivard, L.P. \& Straw, S.B. (2000). The effect of talk and writing on learning science: an exploratory study. Science Education, 84(5), 566-593.

Sasseron, L.H. \& Carvalho, A.M.P. (2011). Construindo argumentação na sala de aula: a presença do ciclo argumentativo, os indicadores de Alfabetização Científica e o padrão de Toulmin. Ciência e Educação, 17, 97-114.

Sasseron, L.H. \& Carvalho, A.M.P. (2011). Uma Análise dos Referenciais Teóricos sobre a Estrutura do Argumento para Estudos de Argumentação no Ensino de Ciências. Ensaio: Pesquisa em Educação em Ciências, 13, 243-262. 